\title{
Segmental artery clamping versus main renal artery clamping in nephron-sparing surgery: updated meta-analysis
}

\author{
Jinhong $\mathrm{Xu}^{1 \dagger}$, Shuxiong $\mathrm{Xu}^{2 \dagger}$, Biao $\mathrm{YaO}^{3}$, Run $\mathrm{Xu}^{3}$, Yuangao $X \mathrm{u}^{2}$, Fa Sun ${ }^{2}$, Qian Qiu ${ }^{4}$ and Hua Shi ${ }^{* *}$
}

\begin{abstract}
Objectives: Ischemia-reperfusion injury is harmful in partial nephrectomy (PN) in renal cell carcinoma. Choosing an appropriate surgical method is important to reduce ischemia-reperfusion injury. This study aimed to compare the effect of segmental artery clamping (SAC) and main renal artery clamping (MAC) on patients who underwent PN.

Methods: Studies from January 2008 to November 2019 were identified by an electronic search of English and Chinese databases, including PubMed, Excerpt Medica Database, Cochrane Library, Wanfang, VIP, and Chinese National Knowledge Internet, without language restriction. Two reviewers were involved in the trial. The effects on operation time (OT), warm ischemia time (WIT), length of hospital stay (LOS), blood transfusion rate, postoperative complication rate, Clavien classification ( $\geq 3$ ), and positive surgery margin (PSM) were evaluated using Stata software. Standardized mean difference (SMD, for continuous data) and pooled odds ratios (for count data) with 95\% confidence interval (Cl) were used as effect indicators.

Results: Thirty-two studies were included. SAC decreased the 1-week (SMD $=-0.973 ; 95 \% \mathrm{Cl}=-1.414,-0.532 ; P$ $=0.000)$, 1-month $(\mathrm{SMD}=-0.411 ; 95 \% \mathrm{Cl}=-0.769,-0.053 ; P=0.025)$, and 3-month (affected kidney: $\mathrm{SMD}=-$ $0.914 ; 95 \% \mathrm{Cl}=-1.662,-0.617 ; P=0.000$ ) percentages of postoperative changes in renal function (estimated glomerular filtration rate) between the SAC and MAC groups. Sub-group analysis showed that the SAC group had longer OT (SMD $=0.562 ; 95 \% \mathrm{Cl}=0.252,0.871 ; P=0.000$ ) than the MAC group. However, no differences were observed in the OT, WIT, LOS, blood transfusion rate, postoperative complication rate, Clavien classification ( $\geq 3$ ), and PSM between the two groups.
\end{abstract}

Conclusions: SAC is superior to MAC in terms of short-term postoperative renal function recovery. The use of SAC or MAC depends on tumor size, location, surgical modality, and surgeon's judgments.

Keywords: Renal cell carcinoma, Segmental arterial clamping, Main arterial clamping, Meta-analysis

\section{Introduction}

Renal cell carcinoma (RCC) is the most lethal malignancy of urinary system tumors and has the second largest incidence with a higher incidence than prostate cancer and a slightly lower incidence than bladder

\footnotetext{
* Correspondence: Hua_Shi6@126.com

† Jinhong Xu and Shuxiong Xu contributed equally to this work.

${ }^{1}$ Tongren City People's Hospital Affiliated to Guizhou Medical University, Tongren 554319, Guizhou, China

Full list of author information is available at the end of the article
}

cancer in North America and Europe [1]. The incidence of asymptomatic small renal cell carcinoma and micro renal cell carcinoma has remarkably increased with the increasing use of imaging for other medical indications by incidental detection [2].

Surgical resection was once the preferred treatment for renal tumors. Radical nephrectomy (RN) and partial nephrectomy (PN), which were first performed by Winfield in 1992, are the two main treatment options [3]. 
PN is appropriate in carefully selected patients with RCC and can reduce the risk of chronic kidney disease (CKD), decrease overall and tumor-specific mortality, and improve long-term renal function compared with RN [4-6]. However, renal artery occlusion is often required, and the accompanying thermal ischemic injury is an important cause of postoperative acute renal failure or long-term CKD [7]. Main renal artery occlusion is an extensive renal blood flow occlusion that blocks the blood supply of tumor and healthy nephrons, and the postoperative recovery of blood flow is bound to lead to the ischemia-reperfusion injury of healthy nephrons [8]. Blocking the renal artery branch that supplies tumor blood with highly selective blockade technology and not blocking the renal artery trunk are safe and feasible in $\mathrm{PN}$, because PN can maintain the normal blood supply of residual kidney tissues and causes no remarkable difference in total renal function [9]. Trehan reported that off-clamp PN is associated with a considerably lower reduction in estimated glomerular filtration rate (eGFR) than on-clamp PN [10]. Robotic partial nephrectomy (RPN) with sequential segmental renal artery (SRA) clamping represents a good alternative for selective patients with multiple ipsilateral renal tumors. Precise segmental artery clamping (SAC) with the guidance of dual-source computed tomography (DSCT) can maximize renal function preservation [11]. Some studies in China reported that SAC is associated with decreased warm ischemia and appears promising in terms of preserving postoperative function [12, 13]. Segmental artery clamping (SAC) was preferred by many surgical doctors. $\mathrm{Li}$ and Zhang [12] showed that SAC is safer and has better renal function preservation compared with main artery clamping (MAC) in $\mathrm{PN}$ by reviewing the previous literature [13]. However, Taweemonkongsap showed that clamping techniques do not affect renal functions, and the complication rate is low even in a small volume center [14]. Therefore, the advantages and disadvantages of SAC and MAC lack systemic elaborations. The indicators for MAC and SAC are unclear. Therefore, tracking and analyzing current research for powerful and systematic evidence are necessary.

In this study, we conducted a retrieval and systematic analysis of the latest literature using case-control studies associated with comparing the features of SAC and MAC. Thus, this study can provide bases for evidencebased medicine to provide better services in clinical diagnosis and treatment.

\section{Methods}

\section{Search strategy and selection criterion}

This meta-analysis complied with the guidelines of the Preferred Reporting Items for Systematic Reviews and Meta-analyses. We selected relevant literature published from January 2008 to November 2019 by searching English and Chinese databases, including Cochrane Library, PubMed, Excerpt Medica Database, Web of Science, China National Knowledge Internet, VIP database, and WanFang database with the following text words and Medical Subject Heading (MeSH) terms: (Kidney neoplasms [MeSH] OR Renal tumor OR Kidney neoplasm OR Neoplasm, Kidney OR Renal neoplasms OR Neoplasm, Renal OR Neoplasms, Renal OR Renal neoplasm OR Neoplasms, Kidney OR Cancer of kidney OR Kidney cancers OR Renal cancer OR Cancer, Renal OR Cancers, Renal OR Renal cancers OR Cancer of the kidney OR Kidney cancer OR Cancer, Kidney OR Cancers, Kidney) AND (Partial nephrectomy OR Nephron sparing nephrectomy OR Nephron sparing surgery OR NSS) AND (Selective arterial clamping OR SAC OR Selective clamp OR Super-selective clamp OR Segmental artery clamp OR Zero ischemia) AND (Main arterial clamping OR MAC) AND (Comparative Study OR Comparative Studies $[\mathrm{MeSH}])$. All eligible tests were considered for review regardless of language.

\section{Inclusion and exclusion criteria}

The patients included were diagnosed with renal tumors, including benign and malignant tumors, and underwent SAC or MAC. Review literature and studies that were not control-case studies were not included in the present study. Documents without the necessary information or containing incomplete basic information were excluded. Low-quality studies were also excluded.

Two researchers (Xu and Zhang) reviewed the related articles separately and extracted the data using a uniform standardized table made with Excel 2010. The researchers preliminarily screened the article titles and abstracts independently. The studies that met the criteria were included in this meta-analysis. Any disagreements were resolved by consulting another researcher (SX Xu) until an agreement was reached. The targeted outcome measures were operating time (OT), estimated blood loss (EBL), warm ischemia time (WIT), blood transfusion rate, length of hospital stay (LOS), postoperative complication rate, postoperative eGFR change value, and percentage decrease in eGFR. In the process of data extraction, the continuous variables expressed using median and quartile spacing were converted to approximate mean and standard deviation, respectively, according to the methods proposed by Luo and Wan, respectively.

\section{Quality evaluation}

The quality of each eligible article was assessed using the Newcastle-Ottawa Quality Assessment Scale (NOS). The papers with scores above 8 points were considered to have high quality. The papers with scores $6-8$ points 
were considered methodologically sound. The studies scoring under 5 points were considered to have low quality and excluded from the final meta-analysis.

\section{Statistical analyses}

Statistical analysis was performed with Stata software version 12.0 (2011) (Stata Corp, Colledge Station, TX, USA). The heterogeneity was assessed using the Cochrane's $Q$ test and the inconsistency index value $\left(I^{2}\right)$. $I^{2}$ was more than $50 \%$, which indicated that there was obvious heterogeneity. A random-effects model was used. A fixed-effects model was used when $I^{2}$ was less than $50 \%$. Otherwise, Descriptive evaluation was adopted for outcome indicators that cannot be quantitatively evaluated. Egger's linear regression test was used to judge publication bias when the number of studies was more than 10 .

\section{Results}

\section{Baseline characteristics of the eligible studies}

A total of 429 studies were identified from a search of the aforementioned databases. Approximately 140 duplicate publications were eliminated after review. Finally, 32 studies, including 19 references in English and 13 references in Chinese, were included in this meta-analysis. These studies had a cumulative sample size of 3098, including 1289 cases in the SAC group and 1809 cases in the MAC group. The flow chart of the literature research phase is shown in Fig. 1. In terms of NOS scores, nine articles had six marks, 11 articles had seven marks, and 12 articles had eight marks. The basic information and NOS scores of the included literature are shown in Table 1. All data retrieved from the reviewed studies and recorded in an electronic database were as follows: demographic characteristics (age, sex, and body mass index), preoperative eGFR, tumor size (maximum

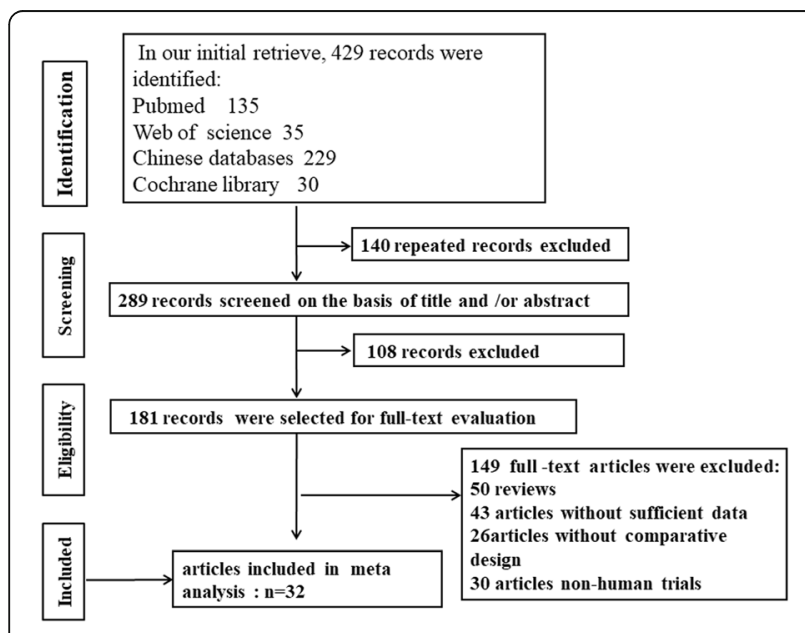

Fig. 1 Flow chart of the included literature diameter), and RENAL marks. The demographic data are shown in Table 2. No significant difference in demographic data was observed between the two groups.

\section{Sensitivity analysis}

Sensitivity analysis (Table 3) showed that OT, EBL, percentage of postoperative change in eGFR ( 1 week, 1 month, 3 months, and 6 months), positive surgery margin (PSM), blood transfusion rate, Clavien classification $(\geq 3)$, and postoperative complications (hemorrhage, hematuria, and urine leak) in the two models were not remarkably different. Therefore, the results regarding these parameters were stable and reliable. By contrast, the results on WIT and LOS were unreliable (Table 3).

\section{Publication bias}

Publication bias for OT, LOS, percentage of postoperative change in eGFR ( 1 week, 1 month, 3 months, and 6 months), PSM, blood transfusion rate, Clavien classification ( $\geq 3$ ), and postoperative complications (hemorrhage, hematuria, and urine leak) was assessed by Egger linear regression. The $P$ values of OT, EBL, and LOS were less than 0.05 , which suggested the presence of publication bias. The $P$ values of the other parameters were greater than 0.05 , which indicated no possibility of publication bias. The results are shown in Table 4.

OT Thirty articles [12-41] were included in the literature. These studies showed heterogeneity $\left(I^{2}=92.3 \%, P\right.$ $=0.000$ ). Therefore, subgroup analysis was made according to different operation methods, namely laparoscopic partial nephrectomy (LPN) and robotic partial nephrectomy (RPN). Minimal heterogeneity was observed between the groups; thus, the operation method was not the main source of the heterogeneity. A random-effect model was used to pool the effectors. The result (Fig. 2) showed that OT was higher in the SAC group than in the MAC group $\left(\mathrm{SMD}=0.56 ; 95 \% \mathrm{CI}=0.25,0.87 ; I^{2}=\right.$ 92.3\%; $P=0.000$ ), and no difference in OT was observed between $\mathrm{SAC}$ and MAC in the RPN group $(\mathrm{SMD}=0.00$; 95\% CI $=-0.38,0.38 ; I^{2}=90.3 \% ; P=0.000$ ).

WIT Twenty-five articles [12-23, 26-29, 31-34, 37, 39, $42,43]$ were included in the literature, and these studies showed heterogeneity $\left(I^{2}=86.4 \%, P=0.000\right)$. Therefore, subgroup analysis was performed according to the different operation methods, LPN and RPN. Slight heterogeneity was found in the different groups, so the operation method was not the main source of heterogeneity. A random-effect model was used to pool the effectors, and the result (Fig. 3) showed no significant difference in the overall WIT between the SAC and MAC groups (SMD $=0.04 ; 95 \% \mathrm{CI}=-0.21,0.28 ; I^{2}=86.4 \% ; P=0.000$ ). 
Table 1 Basic information and remarks of the included papers

\begin{tabular}{|c|c|c|c|c|c|c|c|c|c|c|}
\hline Study & Year & $\begin{array}{l}\text { Type of } \\
\text { study }\end{array}$ & Language & SAC & MAC & $\begin{array}{l}\text { Operation } \\
\text { methods }\end{array}$ & $\begin{array}{l}\text { Observed } \\
\text { indicators }\end{array}$ & $\begin{array}{l}\text { Length of } \\
\text { follow up }\end{array}$ & $\begin{array}{l}\text { NOS } \\
\text { marks }\end{array}$ & $\begin{array}{l}\text { Overall conclusion in SAC } \\
\text { compared with MAC }\end{array}$ \\
\hline Daniele Mattevi & 2018 & Case-control & English & 42 & 15 & RPN & (1)(2)(3)(4)(7)(8) & 1 Mos & 8 & Equivalent (1)(2)(3)(4)(7)(8) \\
\hline $\begin{array}{l}\text { Tawatchai } \\
\text { Taweemonkongsap }\end{array}$ & 2018 & Case-control & English & 38 & 27 & RPN & (1)(2)(3)(4)(5) & 18.2Mos & 8 & $\begin{array}{l}\text { Equivalent (1)(2)(3)(4), less } \\
\text { number of patients with } \\
\text { prolonged WIT }\end{array}$ \\
\hline Gang Xu & 2018 & Case-control & Chinese & 25 & 31 & LPN & (1)(2)(3) & 3 Mos & 8 & $\begin{array}{l}\text { Equivalent (1)(2)(3), superior } \\
\text { postoperative renal function }\end{array}$ \\
\hline Pengtao Wei & 2018 & Case-control & Chinese & 29 & 36 & LPN & (1)(2)(3)(5) & 3 Mos & 7 & $\begin{array}{l}\text { Equivalent (2)(3)(5), more(1), } \\
\text { superior postoperative renal } \\
\text { function }\end{array}$ \\
\hline Yongjian Zhang & 2018 & Case-control & Chinese & 28 & 22 & LPN & (1)(2)(5) & 3days & 7 & $\begin{array}{l}\text { More (1) (3, equivalent (2), } \\
\text { superior postoperative renal } \\
\text { function }\end{array}$ \\
\hline DeZhu Qi & 2017 & Case-control & Chinese & 31 & 32 & LPN & (1)(2)(4)(5)(6) & $12 \mathrm{Mos}$ & 8 & $\begin{array}{l}\text { Equivalent (2)(4)(5), more(1), } \\
\text { superior postoperative renal } \\
\text { function }\end{array}$ \\
\hline Qian Cai & 2017 & $\begin{array}{l}\text { Randomized } \\
\text { controlled } \\
\text { trial }\end{array}$ & Chinese & 15 & 19 & LPN & (1)(2)(5) & $6 \mathrm{Mos}$ & 8 & $\begin{array}{l}\text { Equivalent (2), more (1)(3), } \\
\text { postoperative renal function }\end{array}$ \\
\hline Paulucci & 2016 & $\begin{array}{l}\text { Propensity- } \\
\text { score } \\
\text { analysis }\end{array}$ & English & 66 & 132 & RPN & (1)(2)(3)(5)(2) & $24 \mathrm{Mos}$ & 7 & Equivalent (1)(2)(3)(5)(2) \\
\hline Pu Li & 2016 & & English & 314 & 152 & LPN & (1)(2)(6) & 70Mos & 8 & $\begin{array}{l}\text { Equivalent (1)(2), } \\
\text { postoperative renal function }\end{array}$ \\
\hline Furukawa & 2016 & Case-control & English & 19 & 20 & RPN & (1)(2)(5) & $1 \mathrm{Mo}$ & 7 & $\begin{array}{l}\text { Equivalent (1)(2)(5), } \\
\text { postoperative renal function }\end{array}$ \\
\hline Komninos & 2015 & Case-control & English & 25 & 114 & RPN & (1)(4)(5)(7) & 47Mos & 8 & $\begin{array}{l}\text { Equivalent (1)(4)(56) } \\
\text { superior postoperative renal } \\
\text { function }\end{array}$ \\
\hline Shin & 2015 & Case-control & English & 20 & 97 & RPN & (3)(5)(6) & 3 Mos & 7 & $\begin{array}{l}\text { Equivalent (3)(5)(7), } \\
\text { postoperative renal function }\end{array}$ \\
\hline Akca & 2015 & Case-control & English & 111 & 468 & RPN & (1)(2)(3)(5)(7) & $6 \mathrm{Mos}$ & 7 & $\begin{array}{l}\text { Less (1), equivalent } \\
\text { (2)(3)(5)(2) }\end{array}$ \\
\hline Wu Wei & 2015 & Case-control & Chinese & 39 & 43 & LPN & (2)(3)(5)(7) & $42 \mathrm{Mos}$ & 6 & $\begin{array}{l}\text { Equivalent(2)(3)(6) } \\
\text { postoperative renal function. }\end{array}$ \\
\hline JianZhou Liu & 2015 & Case-control & Chinese & 29 & 27 & LPN & (1)(2)(5) & 36 Mos & 6 & $\begin{array}{l}\text { Equivalent (5) } 7 \text {, more(1)(2), } \\
\text { superior postoperative renal } \\
\text { function }\end{array}$ \\
\hline Peng Li & 2015 & Case-control & Chinese & 10 & 13 & LPN & (1)(4)(5)(6) & $3 \mathrm{Mos}$ & 8 & $\begin{array}{l}\text { More (1)(4), equivalent(5), } \\
\text { superior postoperative renal } \\
\text { function }\end{array}$ \\
\hline Yuan Ruan & 2016 & Case-control & Chinese & 45 & 45 & LPN & (1)(2)(5) & 22.5Mos & 7 & $\begin{array}{l}\text { Equivalent in (1)(5), less(2), } \\
\text { superior postoperative renal } \\
\text { function }\end{array}$ \\
\hline Hao Yang & 2015 & Case-control & Chinese & 35 & 45 & LPN & (2) & $24 \mathrm{Mos}$ & 6 & $\begin{array}{l}\text { Less (2), superior } \\
\text { postoperative renal function }\end{array}$ \\
\hline JianFeng Zhao & 2015 & Case-control & Chinese & 21 & 21 & LPN & (1)(2)(3)(4)(5)(6) & $\begin{array}{l}\text { Not } \\
\text { mentioned }\end{array}$ & 6 & $\begin{array}{l}\text { More (1), equivalent } \\
\text { (2)(3)(4)(5)(7), superior early } \\
\text { renal function }\end{array}$ \\
\hline LiYong Xing & 2014 & Case-control & Chinese & 27 & 28 & LPN & (1)(5) & $\begin{array}{l}\text { Not } \\
\text { mentioned }\end{array}$ & 6 & Equivalent(1)(5) \\
\hline Harke & 2014 & Case-control & English & 15 & 15 & RPN & (1)(2)(5)(6) & 8days & 7 & $\begin{array}{l}\text { Equivalent (1)(2)(5), superior } \\
\text { postoperative renal function }\end{array}$ \\
\hline McClintock & 2014 & Case-control & English & 42 & 42 & RPN & (1)(2)(5) & 3 Mos & 8 & $\begin{array}{l}\text { Equivalent (1)(2)(5), superior } \\
\text { postoperative renal function }\end{array}$ \\
\hline Yue Gao & 2014 & Case-control & Chinese & 21 & 38 & LPN & (2)(3)(5)(2) & $12 \mathrm{Mos}$ & 6 & More(1),equivalent (3)(5)(7), \\
\hline
\end{tabular}


Table 1 Basic information and remarks of the included papers (Continued)

\begin{tabular}{|c|c|c|c|c|c|c|c|c|c|c|}
\hline Study & Year & $\begin{array}{l}\text { Type of } \\
\text { study }\end{array}$ & Language & SAC & MAC & $\begin{array}{l}\text { Operation } \\
\text { methods }\end{array}$ & $\begin{array}{l}\text { Observed } \\
\text { indicators }\end{array}$ & $\begin{array}{l}\text { Length of } \\
\text { follow up }\end{array}$ & $\begin{array}{l}\text { NOS } \\
\text { marks }\end{array}$ & $\begin{array}{l}\text { Overall conclusion in SAC } \\
\text { compared with MAC }\end{array}$ \\
\hline & & & & & & & & & & $\begin{array}{l}\text { superior postoperative renal } \\
\text { function }\end{array}$ \\
\hline SiMei Zhu & 2014 & Case-control & Chinese & 13 & 44 & LPN & (1)(2)(5)(2) & $6 \mathrm{Mos}$ & 7 & $\begin{array}{l}\text { Equivalent (1)(5)(6), more(2, } \\
\text { superior postoperative renal } \\
\text { function }\end{array}$ \\
\hline Desai & 2014 & Case-control & English & 58 & 63 & RPN & (1)(3)(4)(5)(2) & $6 \mathrm{Mos}$ & 7 & $\begin{array}{l}\text { Longer(1), more(4), equivalent } \\
\text { in (3)(5)(3) } 7 \text {, superior renal } \\
\text { function }\end{array}$ \\
\hline Sheng Li & 2014 & Case-control & Chinese & 18 & 38 & LPN & (2)(3)(4)(5) & $4 \mathrm{Mos}$ & 6 & $\begin{array}{l}\text { Equivalent (2)(3)(4)(5), } \\
\text { superior postoperative renal } \\
\text { function }\end{array}$ \\
\hline Borofsky & 2013 & Case-control & English & 27 & 27 & RPN & (1)(3)(4)(5)(6) & 1 Mos & 8 & $\begin{array}{l}\text { Equivalent (1)(3)(4)(5), } \\
\text { superior postoperative renal } \\
\text { function }\end{array}$ \\
\hline Martin & 2012 & Case-control & English & 13 & 32 & RPN & (1)(3)(5) & 3 Mos & 7 & Equivalent (1)(3)(5) \\
\hline JianGang Gao & 2012 & Case-control & Chinese & 42 & 37 & LPN & (1)(2)(3)(4)(5)(7) & 48Mos & 6 & $\begin{array}{l}\text { More (1), less(2), eqiuvalent } \\
\text { (3), superior postoperative } \\
\text { renal function }\end{array}$ \\
\hline $\mathrm{Ng}$ & 2012 & Case-control & English & 22 & 22 & RPN & (1)(2)(3)(4)(5)(6)(7) & $2 \mathrm{Mos}$ & 8 & Equivalent(1)(2)(3)(4)(5)(6)(7). \\
\hline Pengfei Shao & 2011 & Case-control & English & 31 & 37 & LPN & (1)(2)(5) & 33 Mos & 8 & $\begin{array}{l}\text { Equivalent (1)(2)(5), superior } \\
\text { early postoperative affected } \\
\text { renal function }\end{array}$ \\
\hline Nohara & 2008 & Case-control & English & 18 & 27 & $\begin{array}{l}\text { Not } \\
\text { mentioned }\end{array}$ & (1)(2)(5) & 8 Mos & 6 & $\begin{array}{l}\text { Equivalent (1)(2)(5, superior } \\
\text { postoperative renal function }\end{array}$ \\
\hline
\end{tabular}

Note: (1) OT, (2) WIT, (3) PSM, (4) blood transfusion rate, (5) EBL, (6) postoperative complications (Hemorrhage, hematuria, urine leak) (7) LOS, (8) Clavien classification $(\geq 3)$

EBL Thirty articles [12-40, 43, 44] were included, and these studies showed severe heterogeneity $\left(I^{2}=84.3 \%, P\right.$ $=0.000$ ). Therefore, subgroup analysis was made according to the different operation methods, LPN and RPN. The heterogeneity in the different groups changed slightly; thus, the operation method was not the main source of heterogeneity. A random-effect model was then used to pool the effectors. The result (Fig. 4) showed that EBL was higher in the SAC group than in the MAC group $\left(\mathrm{SMD}=0.55 ; 95 \% \mathrm{CI}=0.34,0.75 ; I^{2}=\right.$ $84.3 \% ; P=0.000)$.

Blood transfusion rate Twelve articles [12-14, 24, 26, $29,30,33,35,37,43,44]$ were included, and they showed no heterogeneity $\left(I^{2}=0, P=0.922\right)$. Therefore, a fixed-effect model was used. The results (Fig. 5) revealed no significant difference in the blood transfusion rate between the SAC and MAC groups (odds ratio [OR] = $\left.1.065 ; 95 \% \mathrm{CI}=0.610,1.860 ; I^{2}=0 ; P=0.922\right)$.

LOS Fifteen articles $[16,18,20,24,26,30,31,33-35$, $38,42,43]$ were included, and they showed mild heterogeneity $\left(I^{2}=39.1 \%, P=0.060\right)$. Subgroup analysis was performed according to the operation methods (LPN and RPN). $I^{2}$ value was reduced to some extent in the subgroups; therefore, the operation method was partly the source of the heterogeneity. The results (Fig. 6) showed no significant difference in the LOS between SAC and MAC in the LPN (SMD $=-0.006 ; 95 \% \mathrm{CI}=-$ $\left.0.166,0.154 ; I^{2}=39.1 \% ; P=0.060\right)$ and RPN groups

Table 2 Meta-analysis of demographics of the patients of the included studies

\begin{tabular}{|c|c|c|c|c|c|c|c|c|c|}
\hline \multirow[t]{2}{*}{ Indicators } & \multirow{2}{*}{$\begin{array}{l}\text { Number } \\
\text { of } \\
\text { studies }\end{array}$} & \multirow{2}{*}{$\begin{array}{l}\text { Number } \\
\text { of SAC }\end{array}$} & \multirow{2}{*}{$\begin{array}{l}\text { Number } \\
\text { of MAC }\end{array}$} & \multicolumn{5}{|c|}{ Heterogeneity analysis } & \multirow[b]{2}{*}{$P$ value } \\
\hline & & & & $\overline{x^{2}}$ & df & $P^{2}$ & $P$ value & OR/SMD (95Cl) & \\
\hline Male & 22 & 1072 & 1541 & 157.90 & 21 & 86.70 & 0.31 & $-0.41(-0.39,0.118)$ & 0.27 \\
\hline $\mathrm{BMI}\left(\mathrm{kg} / \mathrm{m}^{2}\right)$ & 21 & 979 & 1441 & 122.30 & 20 & 83.60 & 0.00 & $-0.71(-0.41,0.07)$ & 0.16 \\
\hline RENAL scores & 16 & 841 & 1268 & 80.40 & 15 & 81.30 & 0.00 & $0.15(-0.09,0.40)$ & 0.21 \\
\hline Tumor size(cm) & 22 & 1000 & 1504 & 157.98 & 21 & 86.70 & 0.00 & $-0.14(-0.40,0.40)$ & 0.29 \\
\hline Preoperative eGFR (mL/min/1.73 $\left.\mathrm{m}^{2}\right)$ & 21 & 694 & 1364 & 0.00 & 20 & 0.00 & 1.00 & $0.0(-0.105,0.105)$ & 1.00 \\
\hline
\end{tabular}


Table 3 The pooled effect of outcome indicators

\begin{tabular}{|c|c|c|c|c|}
\hline Outcome indicators & $\mathrm{SMD} / \mathrm{OR}$ & $95 \% \mathrm{Cl}$ & $Z$ value & $P$ 值 \\
\hline \multicolumn{5}{|l|}{ Operation time } \\
\hline LPN & 1.17 & $0.75,1.58$ & 5.54 & 0.000 \\
\hline RPN & 0 & $-0.38,0.38$ & 0 & 0.911 \\
\hline Overall & 0.56 & $0.25,0.87$ & 3.55 & 0.000 \\
\hline \multicolumn{5}{|l|}{ Warm ischemia time } \\
\hline LPN & 0.12 & $-0.25,0.49$ & 0.63 & 0.530 \\
\hline RPN & -0.07 & $-0.42,0.28$ & 0.38 & 0.702 \\
\hline Overall & 0.04 & $-0.21,0.28$ & 0.3 & 0.761 \\
\hline \multicolumn{5}{|l|}{ Estimated blood loss } \\
\hline LPN & 0.65 & $0.35,0.95$ & 4.29 & 0.000 \\
\hline RPN & 0.41 & $0.11,0.71$ & 2.7 & 0.007 \\
\hline Overall & 0.55 & $0.34,0.75$ & 5.1 & 0.000 \\
\hline \multicolumn{5}{|l|}{ Length of hospital stay } \\
\hline LPN & -0.131 & $-0.355,0.092$ & 1.15 & 0.317 \\
\hline RPN & 0.152 & $-0.019,0.322$ & 1.74 & 0.182 \\
\hline Overall & -0.006 & $-0.166,0.154$ & 0.08 & 0.060 \\
\hline 1-week postoperative change percentage in eGFR & -0.97 & $-1.41,-0.53$ & 4.32 & 0.000 \\
\hline 1-month postoperative change percentage in eGFR & -0.41 & $-0.77,-0.05$ & 2.25 & 0.025 \\
\hline 3-month postoperative change percentage in eGFR & -0.26 & $-0.59,0.07$ & 1.54 & 0.124 \\
\hline 6-month postoperative change percentage in eGFR & -0.08 & $-0.40,0.56$ & 0.33 & 0.741 \\
\hline Positive surgical margin & 1.173 & $0.547,2.517$ & 0.41 & 0.908 \\
\hline Blood transfusion rate & 1.065 & $0.610,1.860$ & 0.22 & 0.825 \\
\hline Clavien classification( $\geq 3$ ) & 0.89 & $0.507,1.564$ & 0.4 & 0.686 \\
\hline Postoperative complications (hemorrhage, hematuria, urine leak ) & 0.816 & $0.601,1.107$ & 1.31 & 0.191 \\
\hline
\end{tabular}

$\left(\mathrm{SMD}=0.152 ; 95 \% \mathrm{CI}=-0.019,0.322 ; I^{2}=15.2 ; P=\right.$ 0.317).

Postoperative complications (hemorrhage, hematuria, and urine leak) Twenty-four articles [12, 13, 15, 18-22, $24,26-35,37,38,42-45$ ] were included, and they had no heterogeneity $\left(I^{2}=0, P=1.00\right)$. Therefore, a fixed- effect model was used. The result (Fig. 7) showed no significant difference in the postoperative complications between the $\mathrm{SAC}$ and $\mathrm{MAC}$ groups $(\mathrm{OR}=0.82 ; 95 \% \mathrm{CI}=$ $0.60,1.11 ; P=0.191)$.

Clavien classification $(\geq 3)$ Fifteen articles [13, 14, 19, $27-31,33-35,37,38,44,45]$ were included, and no

Table 4 Egger linear regression results of outcome indicators

\begin{tabular}{lc}
\hline Outcome indicators & $P$ value of Egger test \\
\hline Operation time & 0.027 \\
Warm ischaemia time & 0.287 \\
Estimated blood loss & 0.012 \\
Length of hospital stay & 0.008 \\
1-week postoperative change percentage in eGFR & 0.457 \\
1-month postoperative change percentage in eGFR & 0.744 \\
3-month postoperative change percentage in eGFR & 0.126 \\
6-month postoperative change percentage in eGFR & 0.898 \\
Positive surgical margin & 0.827 \\
Blood transfusion rate & 0.953 \\
Clavien classification ( $\geq$ 3) & 0.176 \\
Postoperative complications (hemorrhage, hematuria, urine leak ) & 0.314 \\
\hline
\end{tabular}




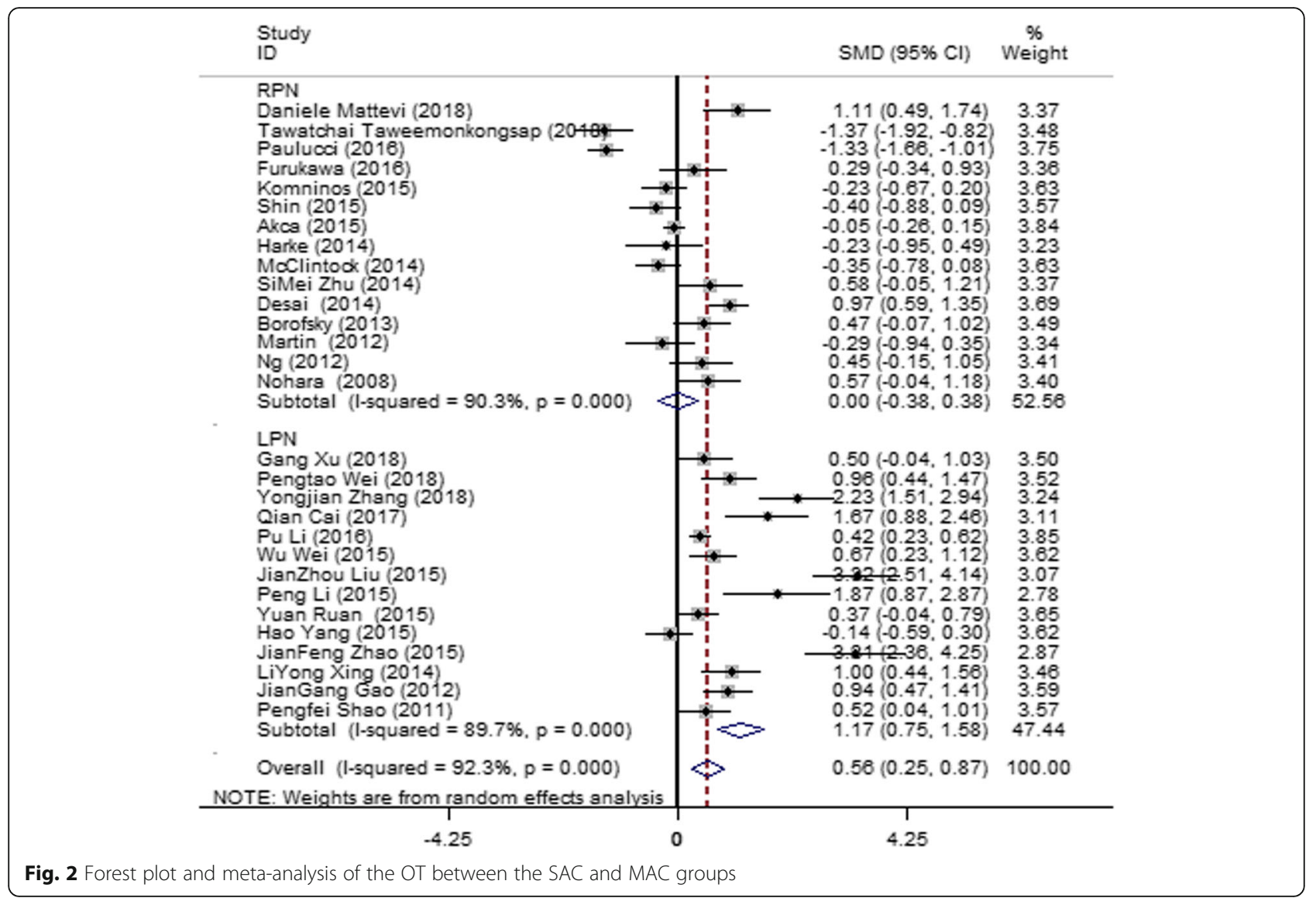

heterogeneity was found among the studies $\left(I^{2}=0, P=\right.$ 0.983). Therefore, a fixed-effect model was used. The result (Fig. 8) showed no significant difference in the Clavien classification between the $\mathrm{SAC}$ and MAC groups $\left(\mathrm{OR}=0.89 ; 95 \% \mathrm{CI}=0.51,1.56 ; I^{2}=0 ; P=0.983\right)$.

PSM Twenty-three articles [14-17, 20-22, 24, 26, 27, 29-35, 37, 38, 43-45]were included. No heterogeneity was observed among the studies $\left(I^{2}=0, P=0.908\right)$, so a fixed-effect model was used. The result (Fig. 9) showed no significant difference in the PSM between the SAC and MAC groups $(\mathrm{OR}=1.17 ; 95 \% \mathrm{CI}=0.55,2.52 ; P=$ 0.908).

One-week postoperative change percentage in eGFR Eight articles [15, 28-30, 32, 33, 35, 42] were included, and severe heterogeneity was observed among the studies $\left(I^{2}=80.7 \%, P=0.000\right)$. Subgroup analysis was performed according to the operation methods, LPN and RPN. $I^{2}$ value was reduced to some extent in the subgroups; therefore, the operation method was partly the heterogeneity source. The result (Fig. 10) showed that the SAC group had a lower change in eGFR than the MAC group in the LPN (SMD $=-1.95 ; 95 \% \mathrm{CI}=-$ $\left.2.90,-1.01 ; I^{2}=62.5 \% ; P=0.103\right)$ and the RPN groups
$\left(\mathrm{SMD}=-0.69 ; 95 \% \mathrm{CI}=-1.00,-0.38 ; I^{2}=56.7 \% ; P=\right.$ 0.041) 1 week after the operation.

One-month postoperative change percentage in eGFR Six articles [27-29, 32, 33, 45] were included, and they showed moderate heterogeneity $\left(I^{2}=62.7 \%, P=0.020\right)$. Therefore, a random-effect model was used. The result (Fig. 11) showed that the SAC group had a lower change in eGFR than the MAC group 1 month after the operation $(\mathrm{SMD}=-0.41 ; 95 \% \mathrm{CI}=-0.77,-0.05 ; P=$ $0.025)$.

Three-month postoperative change percentage in the total eGFR of both kidneys Six articles [19, 27, 29, 30, $33,42]$ were included and showed severe heterogeneity $\left(I^{2}=72.0 \%, P=0.003\right)$. Subgroup analysis was performed according to the operation methods, LPN and RPN. $I^{2}$ value was changed to some extent in the subgroups; therefore, the operation method was the source of heterogeneity in the LPN group but not in the RPN group. A random-effect model was used, and the result (Fig. 12) showed that the postoperative change percentages in the eGFR between the SAC and MAC groups at 3 months after the operation were not significantly different $(\mathrm{SMD}=-0.35 ; 95 \% \mathrm{CI}=-0.72,0.03)$. 


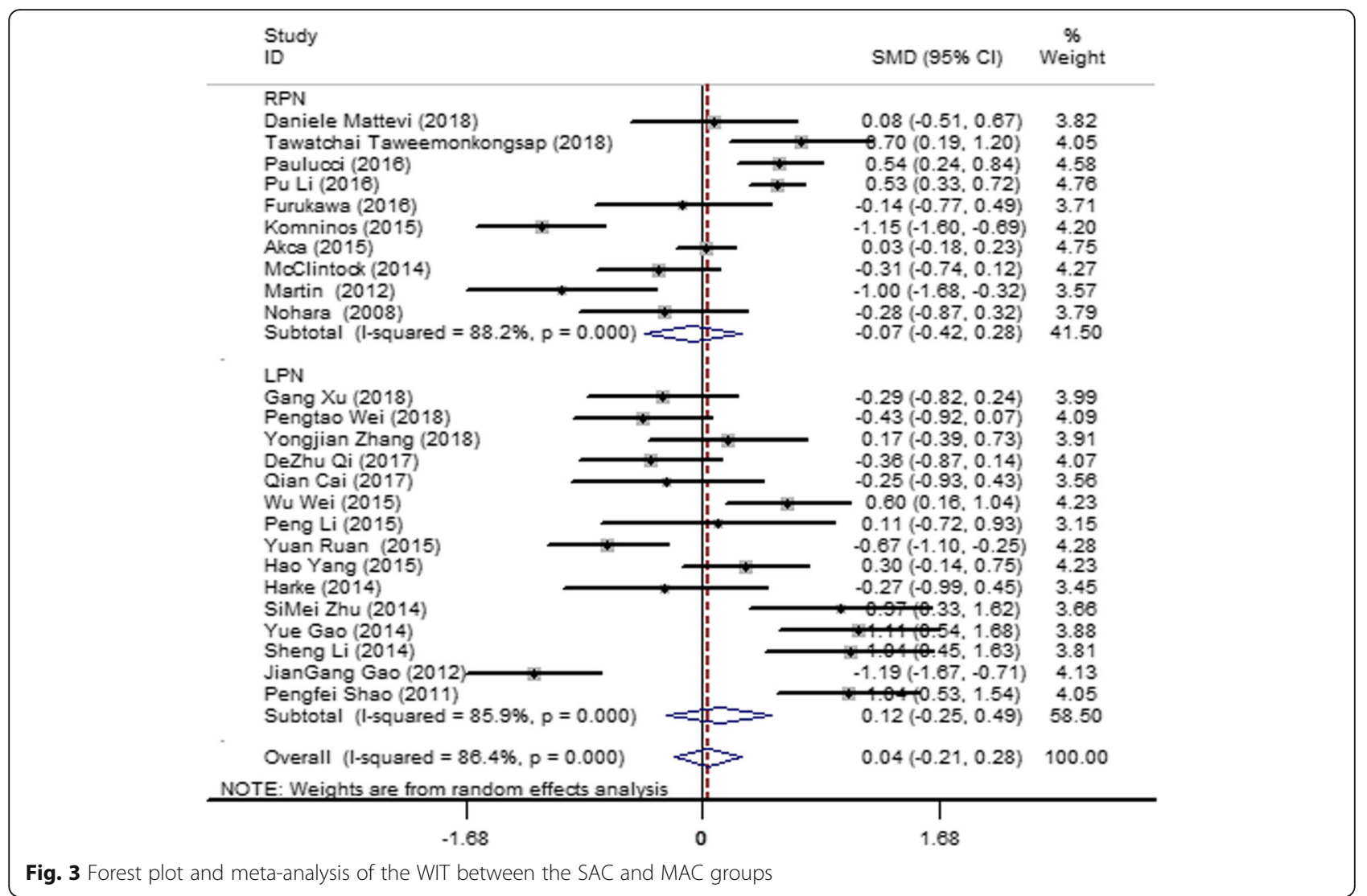

Three-month postoperative change percentage in the eGFR of the affected kidney Three articles [12, 13, 34] were compared, and they and they exhibited severe heterogeneity $\left(I^{2}=87.7 \%, P=0.003\right)$. Therefore, a randomeffect model was used. The result (Fig. 13) showed that the 3-month postoperative change percentage in the eGFR of the affected kidney was lower in the SAC group than in the MAC group $(\mathrm{SMD}=-0.662 ; 95 \% \mathrm{CI}=-$ $0.840,-0.484 ; P=0.000)$.

Six-month postoperative change percentage in the eGFR of both kidneys Four articles [19, 29, 31, 35] were included, and the articles had severe heterogeneity $\left(I^{2}=84.0 \%, P=0.000\right)$. Therefore, a random-effect model was used. The result (Fig. 14) showed no significant difference in the 6-month postoperative change percentage in the eGFR between the SAC and MAC groups $(\mathrm{SMD}=0.081 ; 95 \% \mathrm{CI}=-0.398,0.560 ; P=$ $0.741)$.

\section{Discussion}

In the current study, we systemically evaluated the effect of SAC and MAC on OT, EBL, WIT, LOS, postoperative complication rate, and postoperative percentage decrease in eGFR. The doctors conducted a case-control study by dividing the patients into the SAC and MAC groups.
However, some patients included in the SAC group were subjected to MAC because of excessive bleeding from the defect, insufficient time to modulate the clamped branches, or no satisfactory ischemic area was obtained by clamping multiple branches. The two operations can be interchanged when necessary. Shao et al. first reported the nephrectomy of selectively blocking the renal artery and learned that SAC retains the affected nephrons and reduces the disadvantages of renal ischemic injury [13]. RPN with SRA clamping under the guidance of DSCT and skilled robotic experience is feasible and can maximize renal function preservation [46]. However, large-scale multicenter clinical studies are still needed to further prove these results.

Our results showed that OT was slightly longer in the LPN with SAC group than in the LPN with MAC group, whereas no difference was observed in the RPN group. $\mathrm{PN}$ with SAC requires the separation of the anterior and posterior branches of the renal artery and segmental renal arteries compared with traditional PN with MAC. The kidney should be slightly cut open to separate the third- and fourth-grade renal artery branches when necessary. Doing so requires additional steps and prolongs surgery. The duration of vessel separation during surgery is related to the doctor's skill and familiarity with the anatomical location of blood vessels. In addition to the 


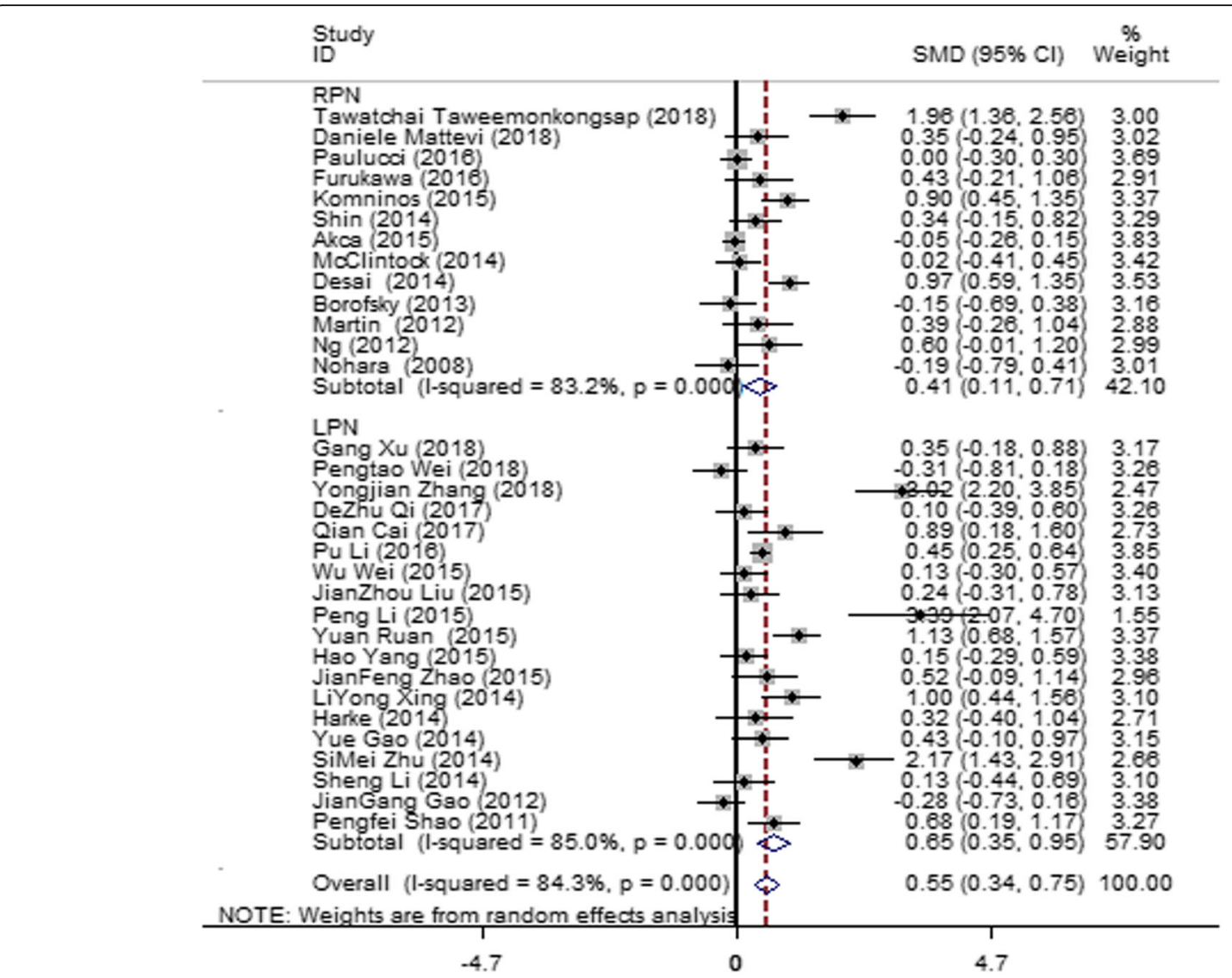

Fig. 4 Forest plot and meta-analysis of the EBL between the SAC and MAC groups

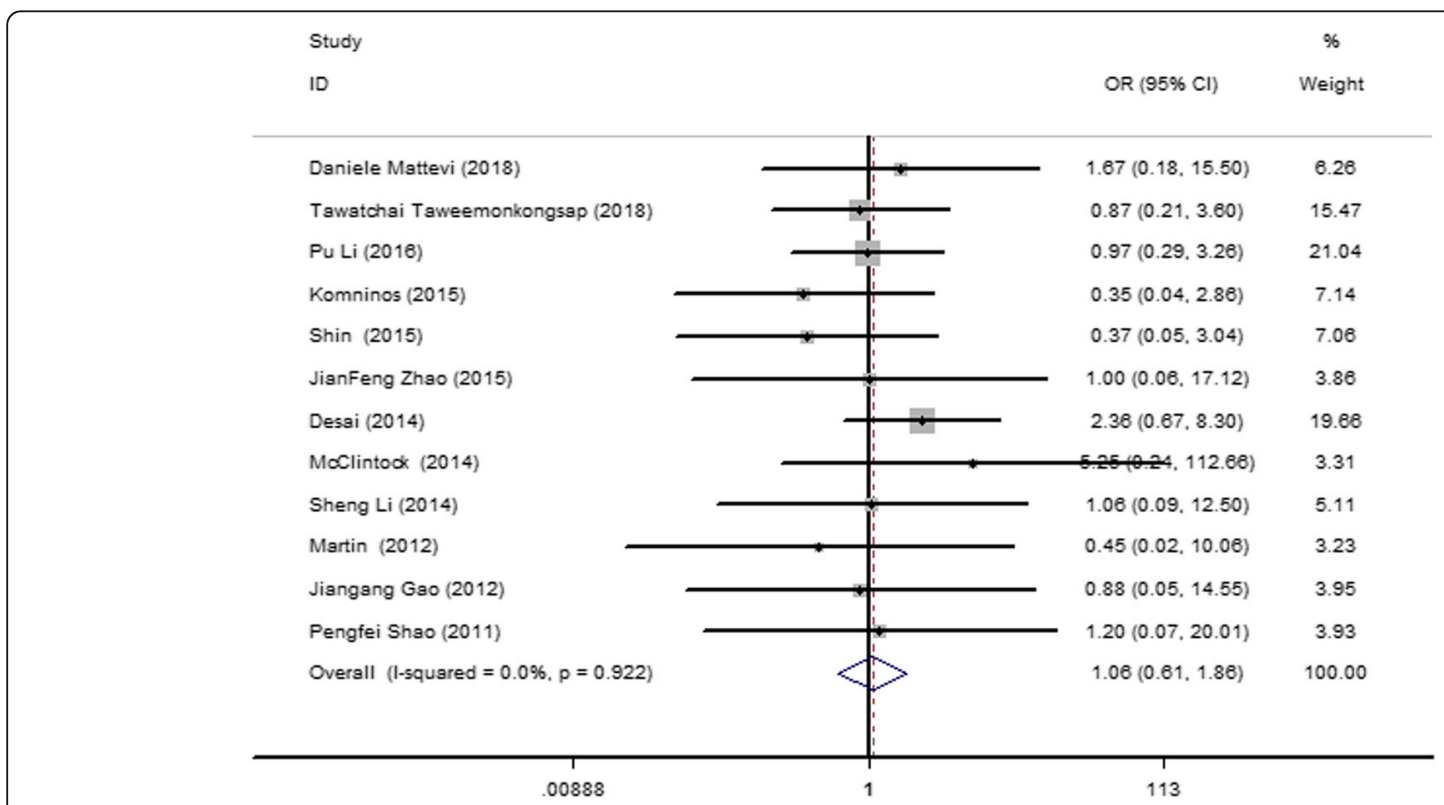

Fig. 5 Forest plot and meta-analysis of the blood transfusion rate between the SAC and MAC groups 


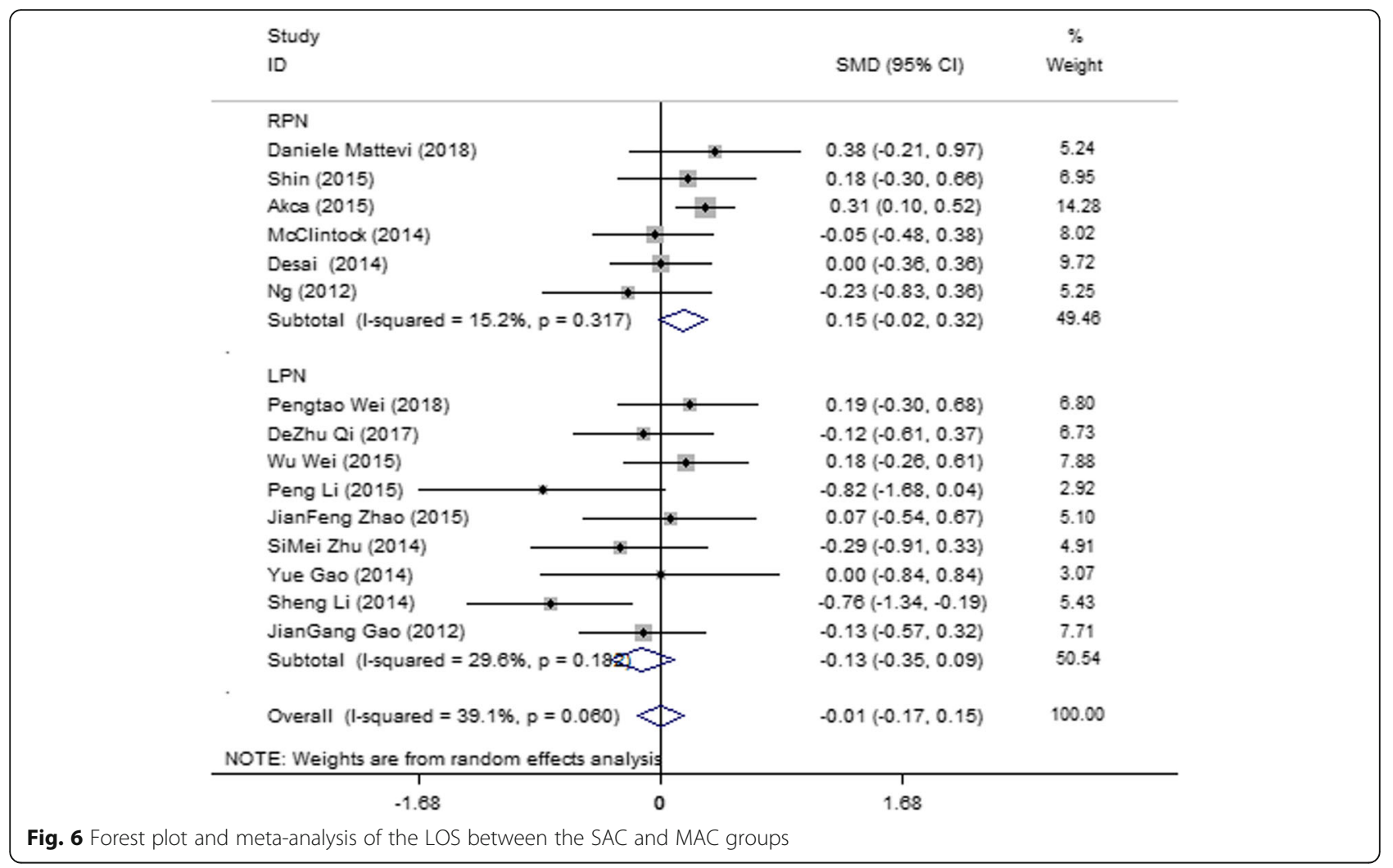

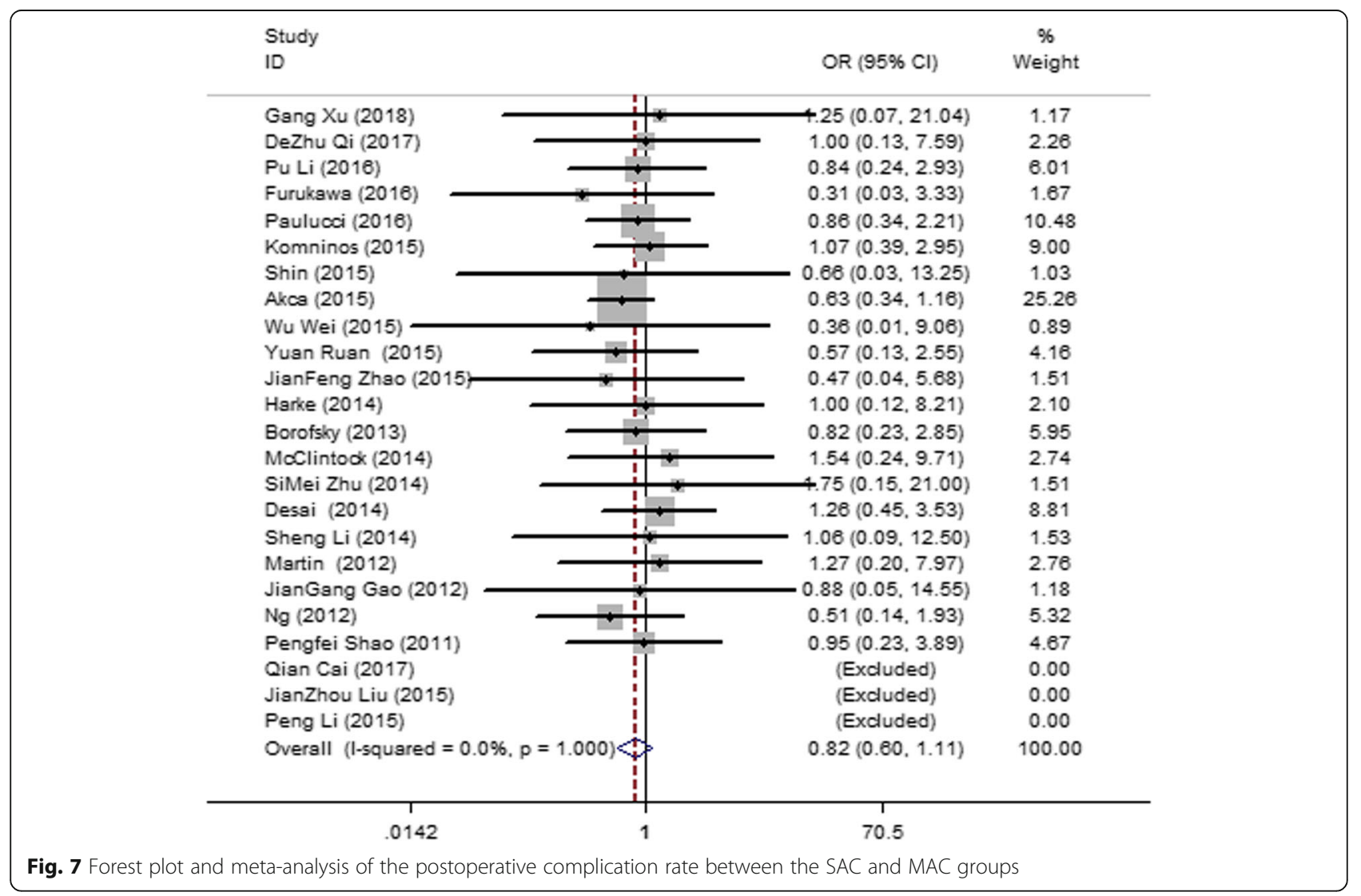




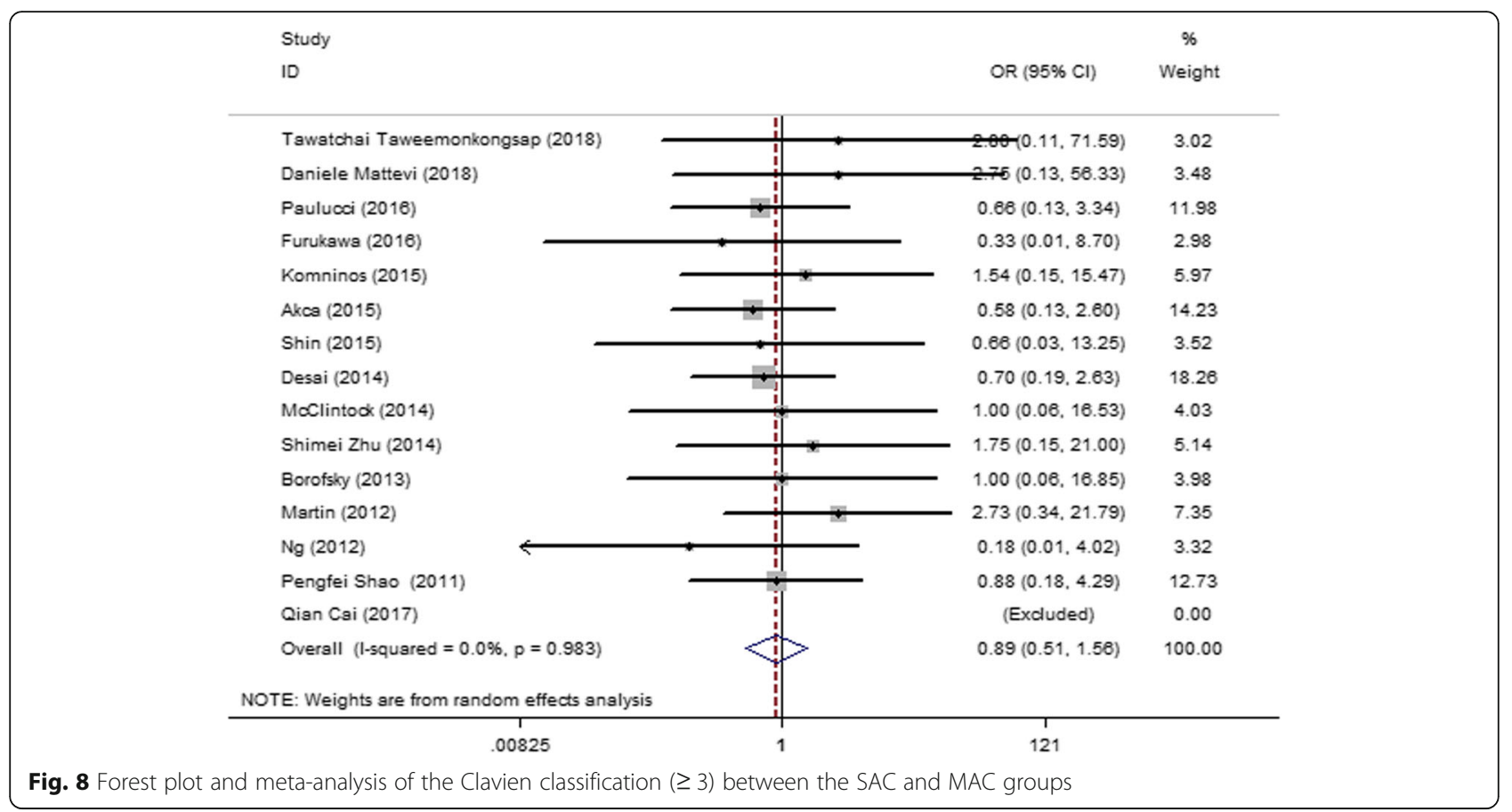

duration of surgery, WIT was emphasized because it is a key factor that affects renal function.

Ischemia-reperfusion injury is a major cause of acute ischemic renal injury. Temporarily blocking the renal pedicle vessels is necessary during $\mathrm{PN}$ to control intraoperative hemorrhage and maintain clear vision, but this procedure can cause renal ischemia-reperfusion injury [47]. LPN is widely used in the surgical treatment of renal tumors because of its safe and effective minimally invasive features. LPN with MAC has a good operative

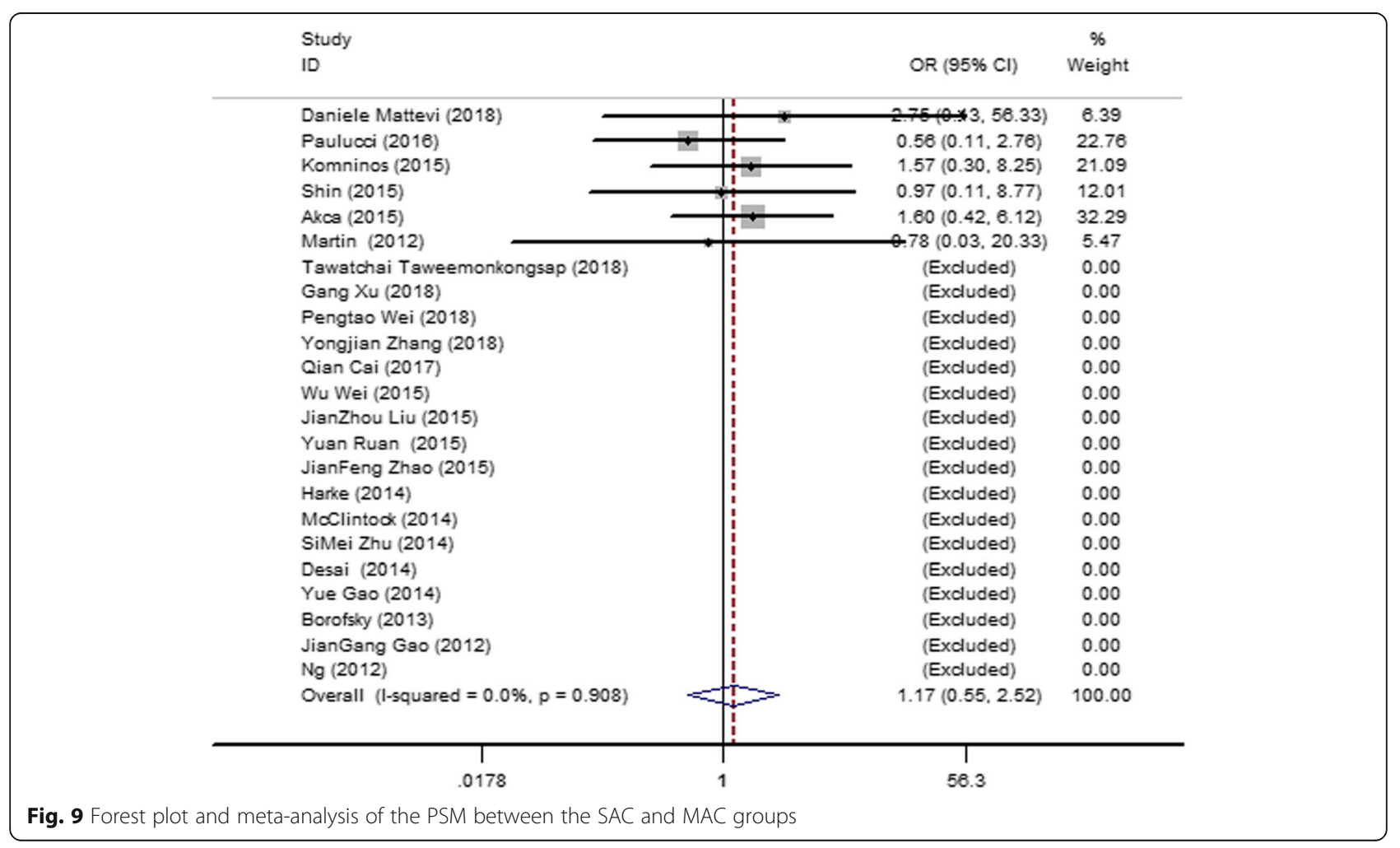




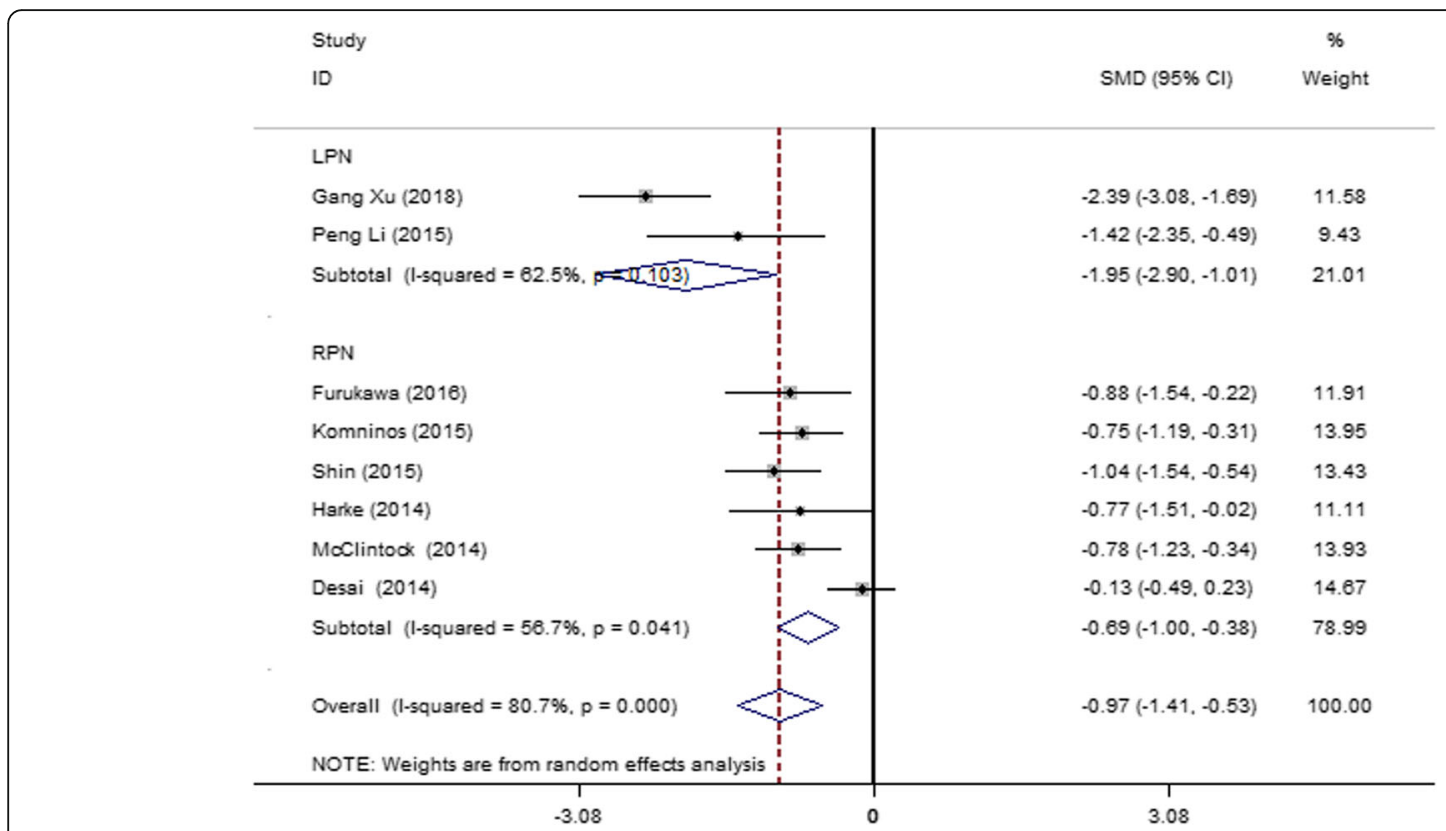

Fig. 10 Forest plot and meta-analysis of the 1-week postoperative change percentage in the eGFR between the SAC and MAC groups

field, but long-term heat ischemia will cause damage to renal function [48, 49]. Benway showed that branch occlusion remarkably reduces thermal ischemia-reperfusion injury in a pig kidney model [50]. Selective renal artery branch blocking technology has been gradually used in PN. The technology only blocks the renal artery branch that supplies blood to the tumor and can effectively avoid or reduce thermal ischemia injury in the normal renal unit. A WIT over $30 \mathrm{~min}$ will produce irreversible damage to kidney function. However, WIT is difficult to control in deeper positions, especially for cases in which the drainage system should be sutured. This meta-analysis showed that OT was longer in the SAC group than in the MAC group in LPN, but no significant difference was observed in the OT between the SAC and MAC groups in RPN. In addition, no significant difference was observed in the WIT between the SAC and MAC groups. LOS is affected by several factors, including a patient's condition. Our study showed no

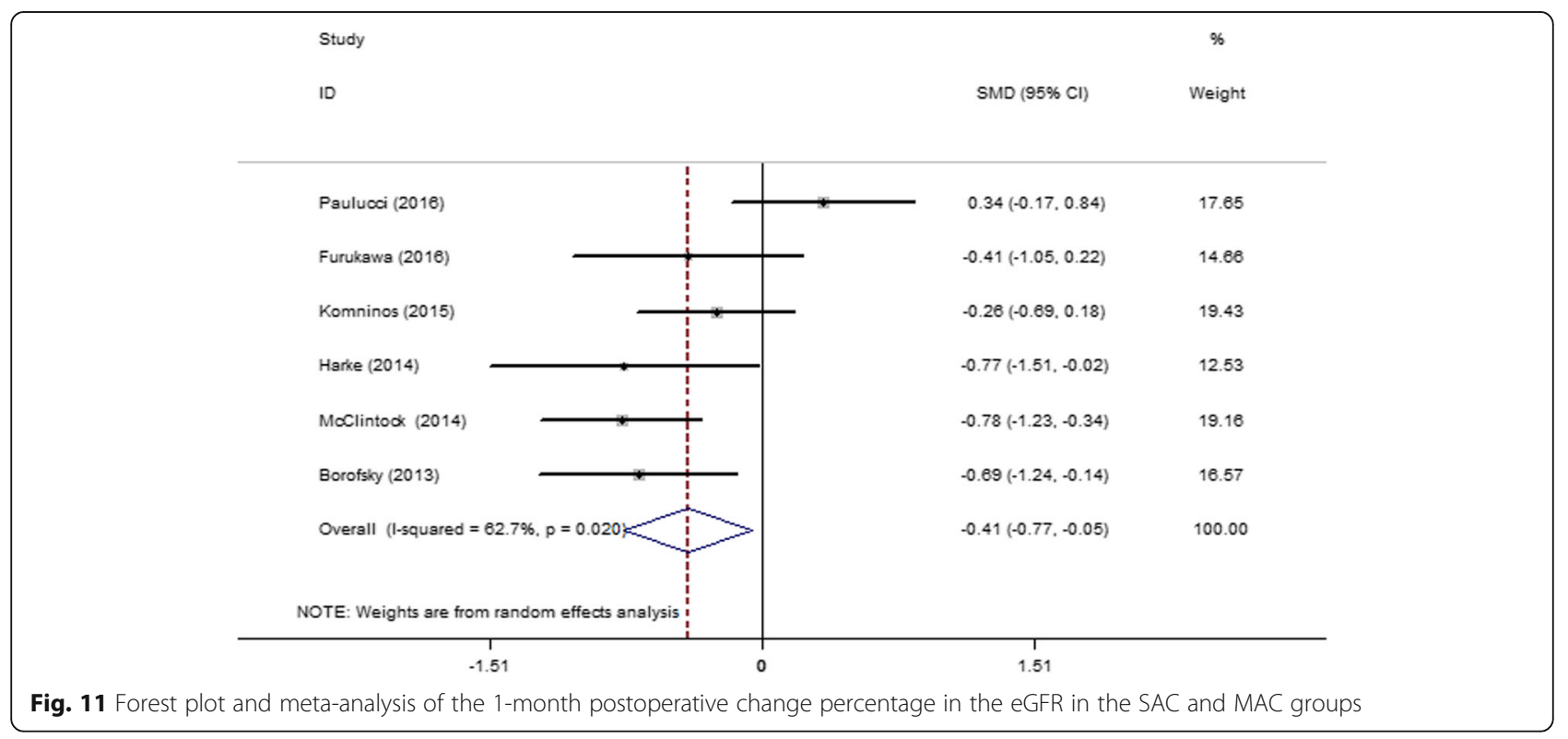




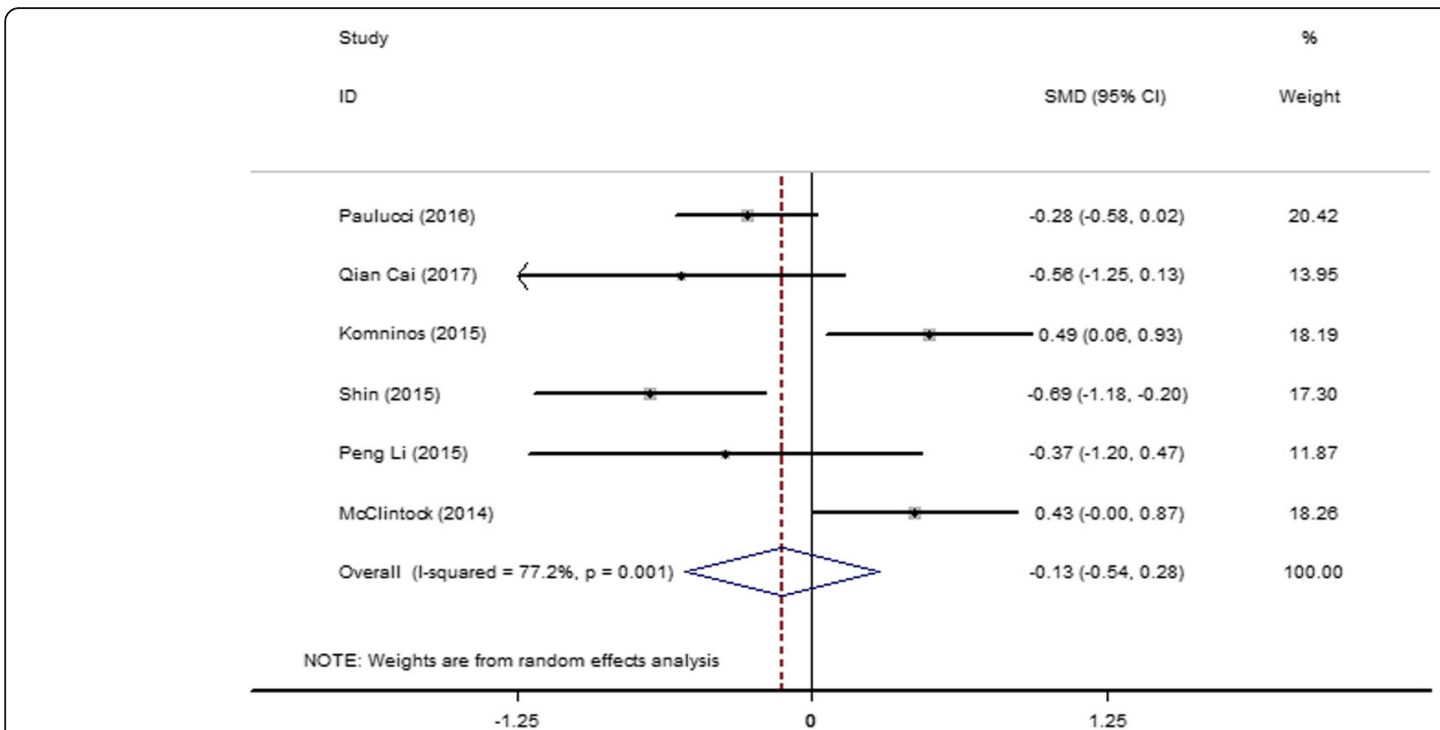

Fig. 12 Forest plot and meta-analysis of the 3-month postoperative change percentage in the total eGFR between the SAC and MAC groups

obvious difference in LOS between PN with SAC and PN with MAC; thus, PN with SAC did not affect LOS.

The results showed that EBL was greater in the SAC group than in the MAC group $(P=0.000)$. However, no significant difference was observed in the blood transfusion rate between the SAC and MAC groups. The combined effect indicator showed a difference between the two groups, but the amount of bleeding is commonly associated with a doctor's experience and skill. The kind of operation adopted depends on the ability of the doctor and the patient's condition. Seventeen of 23 articles showed that none of the patients had PSM. The remaining six articles showed no difference in PSM between the SAC and MAC groups. The combined effect indicator also proved that no difference was observed between the two groups $(P=0.8)$. Thus, no remarkable difference was found in the postoperative complications (hemorrhage, hematuria, and urine leak) and Clavien classifications $(\geq 3)$ between the SAC and MAC groups. Heterogeneity analysis showed no heterogeneity among these studies.

The eight articles $[15,28-30,32,33,35,40]$ related to 1 -week postoperative change percentage in eGFR, which were eligible for this meta-analysis, indicated that the SAC group had lower changes than the MAC group in LPN and RPN. The six articles [27-29, 32, 33, 36] related to the 1-month postoperative change percentage in

\begin{tabular}{|l|l|l|l|}
\hline Study & \\
Simei Zhu (2014) & & \\
Fig. 13 Forest plot and meta-analysis of the 3-month postoperative change percentage in the eGFR of the affected kidney between the SAC and \\
MAC groups
\end{tabular}




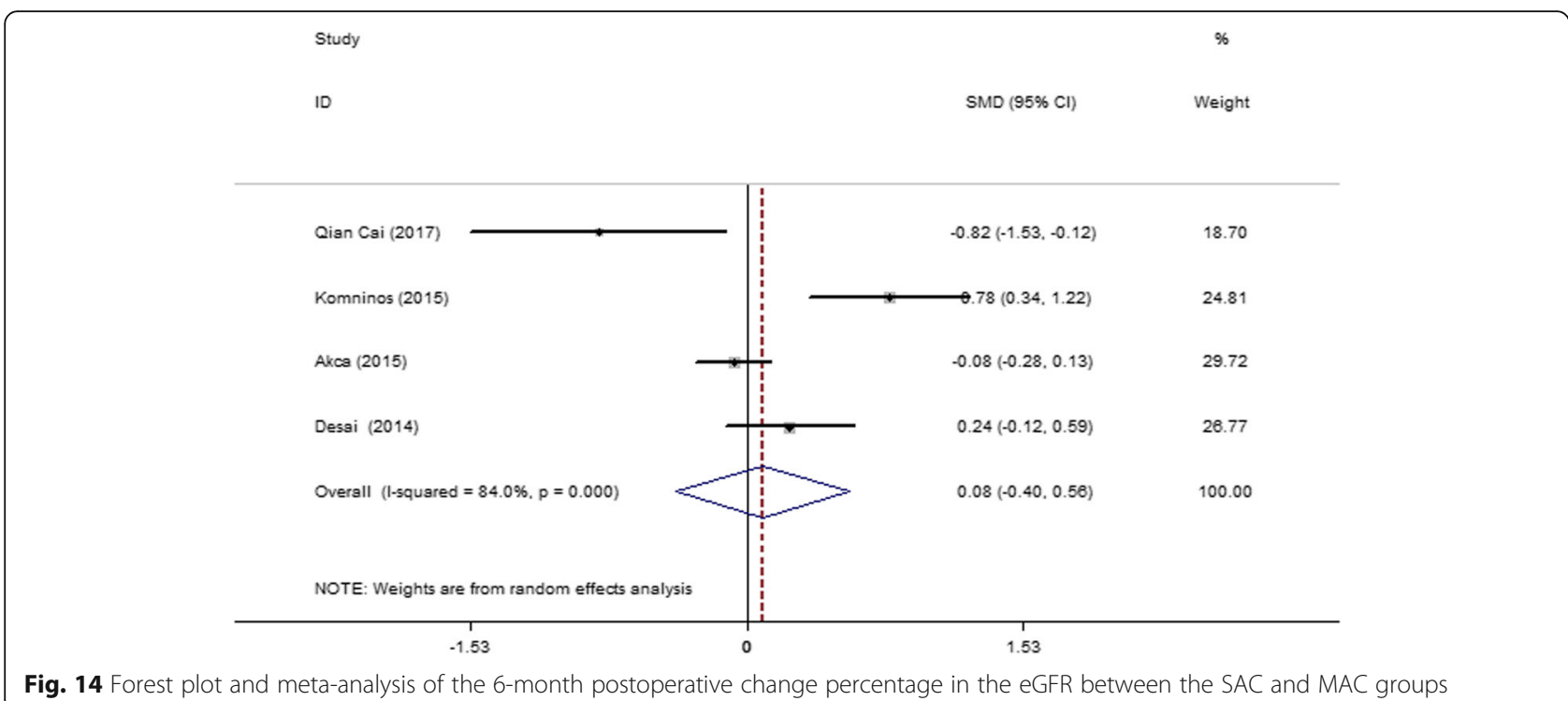

eGFR indicated that the SAC group had lower changes than the MAC group. The six articles [19, 27, 29, 30, 33, 42] related to the 3-month postoperative change percentage in the total eGFR of both kidneys indicated that the SAC and MAC groups had no significant difference in postoperative change in eGFR after 3 months of operation. The three articles $[12,13,34]$ related to the 3month postoperative change percentage in the eGFR of the affected kidney showed severe heterogeneity and indicated that the SAC group had lower changes in eGFR than the MAC group after 3 months of operation. The four articles $[19,29,31,35]$ related to the 6 -month postoperative change percentage in the total eGFR of both kidneys showed severe heterogeneity and indicated that the two groups had no significant difference in eGFR change after 6 months of operation.

The number of articles investigating eGFR change ranged from 3 to 10 . Our study showed that SAC reduced the percentage change in eGFR within 3 months but had no obvious effect on eGFR in 6 months. An analysis of eGFR change beyond 6 months was not carried out because of the lack of related literature. No kidney function loss by 18 months (median) of follow up was observed in $\mathrm{T}$ Taweemonkongsap's study. The present study suggested that SAC had a certain advantage in the short-term recovery of renal function, and this finding requires more random clinical experiments for verification. Our study results provide a basis for surgeons to actively screen and adapt patients to perform branch occlusion. Some patients might be good candidates for SAC. The patients with a tumor near the center of the renal hilum and those with large tumors may benefit from SAC. Komninos [29] suggested that patients who have tumors near the renal hilum, a solitary kidney, or preoperative renal damage are suitable for SAC. Desai
[35] reported that interior, central, and bipolar tumors are suitable for SAC. Martin [37] indicated that SAC is easier to conduct on the right side because the right main renal artery is longer and offers more space for branch dissection than the left side.

\section{Deficiencies}

A large number of literature have been searched according to the inclusion and exclusion criteria; however, most of the studies included in this paper were not (RCTs), and many of the data were expressed in different ways. Some data were calculated by transforming the median and quartile into mean and standard deviation, respectively. Different articles varied in the expression index of kidney function. Some studies used eGFR, whereas others used blood creatinine; therefore, merging the data was difficult. And the surgeon experience, volume, as well as the closure technique cannot be controlled in the analysis. Moreover, the research results showed publication bias in three indicators.

\section{Conclusion}

The current result suggests that SAC is superior to MAC in terms of short-term postoperative renal function recovery. SAC is safe for selective patients when performed by a skilled surgeon. No clear differences in OT, WIT, LOS, blood transfusion rate, and postoperative complications were observed when compared with the alternative (i.e., SAC vs. MAC). However, RCTs are needed to support these preliminary findings.

\section{Abbreviations}

Cl: Confidence interval; SMD: Standard mean deviation; SAC: Segmental artery clamping; MAC: Main artery clamping; PN: Partial nephrectomy; PSM: Positive surgery margin; eGFR: Estimated glomerular filtration rate: OT: Operation time; WIT: Warm ischemia time; LOS: Length of hospital stay 


\section{Acknowledgments}

We would like to thank Deepa Chaphekar (Submission Editor, Springer Nature) for Journal Recommendations and Dr. Jinlan Xu (Jiuying township health center, Panzhou City, Guizhou province, China) for critical checking the data of the manuscript.

\section{Availability of data and material}

We declared that data and material described in the manuscript will be freely available to any scientist without commercial purposes, without breaching participant confidentiality.

\section{Authors' contributions}

JHX, XXS, BY, RX, LLHS, YGX, FS, and QQ conceived and designed the study And they participated in the literature research, data extraction, data disposal, and manuscript drafting. FS reviewed and edited the manuscript. All authors read and approved the final manuscript.

\section{Funding}

This work was supported by Foundation of Guizhou Provincial Science and Technology Department [(2016)1090], United Foundation of Guizhou Provincial Science and Technology Department and Guizhou Provincial Hospital [(LH(2016))7149], and Science and Technology Program of Guiyang City[(20161001)31].

\section{Ethics approval and consent to participate}

This article does not contain any studies with animals performed by any of the authors.

\section{Consent for publication}

The manuscript is approved by all authors for publication.

\section{Competing interests}

The authors declare that they have no conflict of interests.

\section{Author details}

'Tongren City People's Hospital Affiliated to Guizhou Medical University, Tongren 554319, Guizhou, China. ${ }^{2}$ Department of Urology, Guizhou Provincial People's Hospital Affiliated to Guizhou Medical University, Guiyang 550002, Guizhou, China. ${ }^{3}$ Department of Oncology, Tongren City People's Hospital Affiliated to Guizhou Medical University, Tongren 554319, Guizhou, China. Institute of Tuberculosis Research, Chongqing Public Health Medical Center, Chongqing 100036, China.

Received: 5 February 2020 Accepted: 5 August 2020

Published online: 16 August 2020

\section{References}

1. Jemal A, Siegel R, Xu J, Ward E. Cancer statistics, 2010. CA Cancer J Clin. 60(5):277-300

2. Chow WH, Devesa SS. Contemporary epidemiology of renal cell cancer. Cancer J. 2008;14(5):288-301.

3. See WA, Fisher RJ, Winfield HN, Donovan JF. Laparoscopic surgical training: effectiveness and impact on urological surgical practice patterns. J Urol. 1993;149(5):1054-7.

4. Weight CJ, Larson BT, Fergany AF, Gao T, Lane BR, Campbell SC, et al. Nephrectomy induced chronic renal insufficiency is associated with increased risk of cardiovascular death and death from any cause in patients with localized cT1b renal masses. J Urol. 2010;183(4):1317-23.

5. Kim SP, Murad MH, Thompson RH, Boorjian SA, Weight CJ, Han LC, et al. Comparative Effectiveness for Survival and Renal Function of Partial and Radical Nephrectomy for Localized Renal Tumors: A Systematic Review and Meta-Analysis. J Urol. 2012.

6. Daugherty M, Bratslavsky G. Compared with radical nephrectomy, nephronsparing surgery offers a long-term survival advantage in patients between the ages of 20 and 44 years with renal cell carcinomas $(</=4 \mathrm{~cm})$ : an analysis of the SEER database. Urol Oncol. 2014;32(5):549-54.

7. Thompson RH, Lane BR, Lohse CM, Leibovich BC, Fergany A, Frank I, et al. Every minute counts when the renal hilum is clamped during partial nephrectomy. Eur Urol. 2010;58(3):340-5.
8. Xu S, Wang Y, Chu Z, Xu Y. HuaShi, Li K, et al. Protective effect of selective segmental renal artery clamping on the remnant solitary-kidney underwent partial nephrectomy. Chinese Journal of Urology. 2015;36(11):854-9.

9. Gill IS, Eisenberg MS, Aron M, Berger A, Ukimura O, Patil MB, et al. "Zero ischemia" partial nephrectomy: novel laparoscopic and robotic technique. Eur Urol. 2010;59(1):128-34.

10. Trehan A. Comparison of off-clamp partial nephrectomy and on-clamp partial nephrectomy: a systematic review and meta-analysis. Urol Int. 2014; 93(2):125-34

11. Shao $P$, Tang $L$, Li $P, X u Y$, Qin $C, C a o$ Q, et al. Precise segmental renal artery clamping under the guidance of dual-source computed tomography angiography during laparoscopic partial nephrectomy. Eur Urol. 2012;62(6): $1001-8$

12. Li P, Qin C, Cao Q, Li J, Lv Q, Meng X, et al. A retrospective analysis of laparoscopic partial nephrectomy with segmental renal artery clamping and parameters that estimate postoperative renal function. Bju International. 2016:118(4):610-7.

13. Shao P, Qin C, Yin C, Meng X, Ju X, Li J, et al. Laparoscopic partial nephrectomy with segmental renal artery clamping: technique and clinical outcomes. European Urology. 2011;59(5):849-55.

14. Taweemonkongsap T, Suk-Ouichai C, Chotikawanich E, Jitpraphai S, Woranisarakul V, Ramart P, et al. The impact of arterial clamping technique in robot-assisted partial nephrectomy on renal function and surgical outcomes: six-year experience at Siriraj Hospital. Thailand. Urol Int. 2018; 100(3):301-8.

15. Xu G, Yan J, Pan S. Zhu z, Li J, Zhou Y, et al. Comparative effectiveness for the treatment of renal tumors of selective renal artery branch blocking and renal artery blocking under laparoscopic partial nephrectomy Zhejiang Medical Journal. 2018;40(8):848-57.

16. Wei P, Qiao B, Zhang H, Sun J, Han X, Lv W. Application of selective renal artery block technique in laparoscopic nephron sparing surgery. China Journal of Endoscopy. 2018;24(1):56-9.

17. Zhang Y. Comparsion of pplication effect between super selective renal artery branch block and renal artery block Contemporary Medicine. 2018;24(1):80-2.

18. Qi D, Yuan X, Ren Y, Sun L, Luo L, Zhang G. Clinical effect of retroperitoneal laparoscopic partial nephrectomy with selective renal artery branch clamping in treatment of renal tumor with a RENAL score of 7. Medical Journal of Qilu. 2017;32(5):505-7.

19. Cai Q. Application of selective renal artery branch blocking in partial nephrectomy.: Dissertation, Kunming medical university.; 2017.

20. Wei W, Wang L, Ge J, Gong J, Xu F. Effect of laparoscopic renal resection of kidney after selective renal artery blocking. Jiangsu Medical Journal. 2015; 41(17):2031-3.

21. Liu J, Luo X, Men Q, Ju Y, Suo J. Evaluation of high-selective renal artery blockage in retroperitoneal laparoscopic nephron-sparing surgery. Journal of Modern Oncology. 2016;24(18):2912-5.

22. Yuan R, Wang XH, Wang K, Zhao YY, Xia SJ, Xu DL. Clinical evaluation and technical features of three-dimensional laparoscopic partial nephrectomy with selective segmental artery clamping. World Journal of Urology. 2016; 34(5):679-85.

23. Yang $\mathrm{H}$, Chen $\mathrm{F}$, Shi J, Li D, Chen C. After comparing with comparsion of impact of postoperative side kidney function between laparoscopic segmental renal artery block ing and complete renal artery blocking partial nephrectomy. Journal of Clinical Urology. 2015;30(5):393-6.

24. Zhao J, Feng Y, He J. Clinical analysis on T1a renal clear cell carcinoma after laparoscopic highly selective renal artery blocking and renal artery blocking treatment stage. International Journal of Urology and Nephrology. 2015; 35(2):233-6.

25. Xing L, Liu C, Yang Y, RuiFa, Liu L. Comparsion of curative effect between laparoscopic highly selective renal artery blocking and whole blocking partial nephrectomy Journal of Clinical Urology. 2014;29(5).

26. Gao J, Hou S, Sun X, Zhu H, Bai X, Zhu L. Comparison of selectivity renal artery interrupted and renal artery interrupted retroperitoneal laparoscopic partial nephrectomy on small renal carcinoma. Journal of laparoscopic surgery. 2012;17(2):103-6.

27. Paulucci DJ, Rosen DC, Sfakianos JP, Whalen MJ, Abaza R, Eun DD, et al. Selective arterial clamping does not improve outcomes in robotic partial nephrectomy; a propensity score analysis of patients without impaired renal function. Bju International. 2016;119(3).

28. Furukawa J, Miyake H, Hinata N, Muramaki M, Tanaka K, Fujisawa M. Renal functional and perioperative outcomes of selective versus complete renal 
arterial clamping during robot-assisted partial nephrectomy: early singlecenter experience with 39 cases. Surgical Innovation. 2015;23(3):242.

29. Komninos C, Shin TY, Tuliao P, Han WK, Chung BH, Choi YD, et al. Renal function is the same regardless of clamp technique 6 months after robotassisted partial nephrectomy: analysis of Off-Clamp, selective arterial clamp and main artery clamp with minimum of 1 year follow-up. Bju International. 2014;115(6):921-8

30. Shin TY, Lim SK, Komninos C, Dong WK, Han WK, Hong SJ, et al. Clinical values of selective-clamp technique in robotic partial nephrectomy. World Journal of Urology. 2015;33(6):763.

31. Akca O, Zargar H. Attalla K. Laydner H, Krishnan J, et al. Possible detrimental affect of clamping main verus segmental renal arteries to achieve global ischemia during robotic partial nephrectomy. Journal of Endourology: Brandao LF; 2015.

32. Nina H, Georg S, Frank S, Elmar H. Selective clamping under the usage of near-infrared fluorescence imaging with indocyanine green in robotassisted partial nephrectomy: a single-surgeon matched-pair study. World Journal of Urology. 2014;32(5):1259-65.

33. McClintock TR, Bjurlin MA, Wysock JS, Borofsky MS, Marien TP, Okoro C, et al. Can selective arterial clamping with fluorescence imaging preserve kidney function during robotic partial nephrectomy? Urology. 2014;84(2): 327-34.

34. Zhu S, Li Z. Laparoscopic partial nephrectomy with highly selective clamping of renal arterial branches. National Medical Journal of China. 2014; 92(12):938-41.

35. Desai MM, Abreu ALDC, Leslie S, Cai J, Huang YH, Lewandowski PM, et al. Robotic Partial nephrectomy with superselective versus main artery clamping: a retrospective comparison. European Urology. 2014;66(4):713-9.

36. Borofsky MS, Gill IS, Hemal AK, Marien TP, Jayaratna I, Krane LS, et al. Nearinfrared fluorescence imaging to facilitate super-selective arterial clamping during zero-ischaemia robotic partial nephrectomy. Bju International. 2013; 111(4):604-10

37. Martin GL, Warner JN, Nateras RN, Andrews PE, Humphreys MR, Castle EP. Comparison of total, selective, and nonarterial clamping techniques during laparoscopic and robot-assisted partial nephrectomy. Journal of Endourology. 2012;26(2):152-6.

38. Ng CK, Gill IS, Patil MB, Hung AJ, Berger AK, Abreu ALDC, et al. Anatomic renal artery branch microdissection to facilitate zero-ischemia partial nephrectomy. European Urology. 2012;61(1):67-74.

39. Nohara T, Fujita H, Yamamoto K, Kitagawa Y, Gabata T. Namiki MJIJoU. Modified anatrophic partial nephrectomy with selective renal segmental artery clamping to preserve renal function: a preliminary report. 2010;15(11): 961-6.

40. Li P, Yang Q, Xiao C. Ji j, Xu B, Chen J, et al. Superselective clamping of renal artery in laparoscopic partial nephrectomy: primary experience sharing. Academic Journal of Second Military Medical University. 2015;36(2): 183-7.

41. Mattevi D, Luciani LG, Mantovani W, Cai T, Chiodini S, Vattovani V, et al. Fluorescence-guided selective arterial clamping during RAPN provides better early functional outcomes based on renal scan compared to standard clamping. J Robot Surg. 2019;13(3):391-6.

42. Li P, Yang Q, Xiao C, Ji J, Xu B, Chen J, et al. Superselective clamping of renal artery in laparoscopic partial nephrectomy: primary experience sharing. Academic Journal of Second Military Medical University. 2015;36(2): 183-7.

43. Gao Y, Li G, Li X, Peng B, Niu Y. Segmental artery clamping versus main renal artery clamping for renal mass. Journal of Contemporary Urologic and Reproductive Oncology. 2014;6(2):73-6.

44. Daniele M, Luciani LG, Mantovani W, Cai T, Chiodini S, Vattovani V, et al. Fluorescence-guided selective arterial clamping during RAPN provides better early functional outcomes based on renal scan compared to standard clamping. Journal of Robotic Surgery.

45. Borofsky MS, Gill IS, Hemal AK, Marien TP, Jayaratna I, Krane LS, et al. Nearinfrared fluorescence imaging to facilitate super-selective arterial clamping during zero-ischaemia robotic partial nephrectomy. Bju International. 2012; 111(4):604-10

46. Yang J, Xia JD, Xue JX, Song NH, Liang C, Xi D, et al. Robotic-assisted partial nephrectomy with sequential clamping of segmental renal arteries for multiple ipsilateral renal tumors: initial outcomes. BMC Urol. 2019;19(1):31.

47. Wszolek MF, Kenney PA, Libertino JA. Nonclamping partial nephrectomy: towards improved nephron sparing. Nature Reviews Urology. 2011;8(9):523.
48. Campbell SC, Mir MC, Zhang Z, Zhao J. Re: Renal ischemia and function after partial nephrectomy: a collaborative review of the literature. European Urology. 2015;68(1):61-74.

49. Shah PH, George AK, Moreira DM, Alom M, Okhunov Z, Salami S, et al. To clamp or not to clamp? Long-term functional outcomes for elective offclamp laparoscopic partial nephrectomy. Bju International. 2016;117(2):2939.

50. Benway BM, Baca G, Bhayani SB, Das NA, Katz MD, Diaz DL, et al. Selective versus nonselective arterial clamping during laparoscopic partial nephrectomy: impact upon renal function in the setting of a solitary kidney in a porcine model. Journal of Endourology. 2009;8(4):127-

\section{Publisher's Note}

Springer Nature remains neutral with regard to jurisdictional claims in published maps and institutional affiliations.
Ready to submit your research? Choose BMC and benefit from:

- fast, convenient online submission

- thorough peer review by experienced researchers in your field

- rapid publication on acceptance

- support for research data, including large and complex data types

- gold Open Access which fosters wider collaboration and increased citations

- maximum visibility for your research: over $100 \mathrm{M}$ website views per year

At BMC, research is always in progress.

Learn more biomedcentral.com/submissions 